\title{
Effect of Nutrient Metabolism on Cartilaginous Tissue Formation
}

\author{
Roberto Tarantino ${ }^{1}$, Loraine Chiu ${ }^{1}$, Joanna Weber $^{2}$, Yat Tse ${ }^{3}$, Davide Bardana ${ }^{3}$, Stephen \\ Pang $^{3}$, and Stephen Waldman ${ }^{1}$ \\ ${ }^{1}$ Ryerson University \\ ${ }^{2}$ St Michael's Hospital Li Ka Shing Knowledge Institute \\ ${ }^{3}$ Queen's University
}

January 23, 2021

\begin{abstract}
Despite the potential of tissue engineering approaches for cartilage repair, a major shortcoming is the low biosynthetic response of chondrocytes. While different strategies have been investigated to upregulate tissue formation, a novel approach may be to control nutrient metabolism. Although known for their anaerobic metabolism of glucose, chondrocytes are more synthetically active when cultured under conditions that elicit mixed aerobic-anaerobic metabolism. Here, we postulate this metabolic switch induces hypoxia inducible factor $1 \alpha(\mathrm{HIF}-1 \alpha)$ signaling leading to improved tissue growth. Transition to different metabolic states can result in the pooling of intracellular metabolites, several of which can stabilize HIF-1 $\alpha$ by interfering with prolinehydroxylase-2 (PHD2). Chondrocytes cultured under increased media availability accelerated tissue deposition (2.2 to 3.5-fold) with the greatest effect occurring at intermediate volumes $(2 \mathrm{~mL} / 106$ cells $)$. Under higher media volumes, metabolism switched from anaerobic to mixed aerobic-anaerobic. At and beyond this transition, maximal changes in PHD2 activity (- 45\%), HIF-1 $\alpha$ protein expression (8-fold increase), and HIF-1 gene target expression were observed (2.0 to 2.7-fold increase). Loss-of-function studies using YC-1 (to degrade HIF-1 $\alpha$ ) confirmed the involvement of HIF-1 signaling under these conditions. Lastly, targeted metabolomic studies of glucose metabolites (14 in total) revealed that both intracellular lactate and succinate correlated with PHD2 activity. Although both metabolites can inhibit PHD2, this effect can most likely be attributed to lactate as succinate was only present in trace amounts. However, addition work (e.g., 13C flux analyses) are required to confirm this assertion. Nevertheless, by harnessing this newly identified metabolic switch, functional engineered cartilage implants may be developed without the need for sophisticated methods which would allow for improved translation into the clinical realm.
\end{abstract}

\section{Introduction}

Articular cartilage has a limited repair capacity (Hunziker, 1999) leaving it susceptible to damage from trauma or diseases such as osteoarthritis (OA). Although total joint arthroplasty is currently the standardof-care with generally good clinical outcomes, this technique has limited function and longevity in the younger population. Therefore, recent efforts have focused on developing biological-based approaches for cartilage repair. One such promising approach is defect resurfacing with engineered cartilage (Waldman et al. , 2002). While much progress has been made, it still has proven difficult to produce tissue suitable for the repair of clinically-sized defects $\left(2-6 \mathrm{~cm}^{2}\right)$ (Brittberg et al. , 1994). One of the major shortcomings of most cartilage tissue engineering approaches is the generally low accumulation of tissue constituents (Buschmann et al., 1992; Vunjak-Novakovic et al., 1999; Waldman et al. , 2002). To address this challenge, several strategies have been investigated, such as: growth factor stimulation (Chen et al. , 2014; Lam et al. , 2015), gene therapy (Chen et al. , 2014), mechanical stimulation (Waldman et al. , 2003), and bioreactor cultivation (Khan et al. , 2009). While each strategy can accelerate tissue formation, these approaches either rely on use of overly sophisticated methods and/or suffer from off-target effects, thereby requiring substantial efforts to implement or optimize. 
An alternative and straightforward approach may be to control nutrient metabolism. Several studies have demonstrated that increased nutrient availability (primarily by increasing media volume) can improve cartilaginous tissue growth (Mauck et al. , 2003; Heywood et al. , 2006; Khan et al. , 2009; Oze et al. , 2012). While these studies did not identify a particular mechanism, this effect may be due to resultant changes in glucose metabolism (Oze et al. , 2012). Chondrocytes are known for their anaerobic metabolism of glucose (Khan et al. , 2009), even in the presence of oxygen (Warburg-like effect) (Lane et al. , 1977; Suits et al. , 2008). After uptake, glucose is primarily metabolized through the glycolytic and fermentation pathways resulting in the release of lactate. The aerobic pathway is typically not well utilized and little of the pyruvate generated from glycolysis is metabolized through the tricarboxylic acid (TCA) cycle (Lane et al. , 1977). Interestingly however, chondrocytes tend to synthesize more extracellular matrix (ECM) when cultured under conditions that elicit a switch in metabolism from anaerobic to mixed aerobic-anaerobic metabolism (Lane et al. , 1977; Obradovic et al. , 1999; Khan et al. , 2009). We postulate that this metabolic switch may be directed by alterations in hypoxia inducible factor $1 \alpha(\mathrm{HIF}-1 \alpha)$ signaling. The transition to different metabolic states can result in the pooling of intracellular metabolites, several of which have been shown to stabilize HIF-1 $\alpha$ by interfering with proline-hydroxylase-2 (PHD2) (Lu et al. , 2002; Kim et al. , 2010; Ren et al. , 2011; De Saedeleer et al. , 2012; Bailey \& Nathan, 2018); the enzyme responsible for initiating HIF-1 $\alpha$ degradation in the presence of oxygen. For chondrocytes, this pseudo-hypoxic state (hypoxic gene expression in the absence of hypoxia) is especially important as the target genes of HIF-1 affect both chondrogenesis and cartilage homeostasis (Goldring \& Marcu, 2009; Dengler et al. , 2014). Thus, the purpose of this study is to investigate the effect of increasing nutrient availability on glucose metabolism, HIF-1 signaling, and resultant tissue formation by primary articular chondrocytes.

\section{Methods}

\section{Chondrocyte Isolation and Cell Culture}

Full-thickness articular cartilage was aseptically harvested from the metacarpal-phalangeal joints of skeletally-mature bovine (obtained fresh from a local slaughterhouse; 20-24 months of age) to isolate primary chondrocytes by enzymatic digestion (Waldman et al. , 2002). Briefly, cartilage slices were incubated in protease $(0.5 \% \mathrm{w} / \mathrm{v})$ for 1 hour followed by 18 hours in collagenase A $(0.15 \% \mathrm{w} / \mathrm{v})$ in Ham's F-12 media. For each isolation, tissue slices from at least two animals were pooled together to achieve adequate cell numbers. Viable cells (>90\%; by trypan blue dye exclusion) were seeded on collagen II-coated Millicell filters (10 mm dia.; Millipore) in 3D high density culture $\left(2 \times 10^{6}\right.$ cells/filter or 25,000 cells $\left./ \mathrm{mm}^{2}\right)$ (Kaupp \& Waldman, 2008) and maintained in Ham's F12 media containing $10 \mathrm{mM}$ glucose and supplemented with $20 \%$ FBS, $100 \mu \mathrm{g} / \mathrm{mL}$ ascorbate, $20 \mathrm{mM}$ HEPES, and $1 \%$ (v/v) penicillin/streptomycin. Cultures were grown under varying volumes of media $\left(1-8 \mathrm{~mL}\right.$ or $0.5-4 \mathrm{~mL} / 10^{6}$ cells $)$ and maintained under normoxic conditions $\left(5 \% \mathrm{CO}_{2}: 95 \%\right.$ atmospheric air; $95 \%$ relative humidity; $37^{\circ} \mathrm{C}$ ) for 4 weeks with media exchanged every $2-3$ days. The same approach was used for both rabbit chondrocytes (Charles River Laboratories) and human donor chondrocytes; approved by the University Animal Care Committee (Queen's University) and Research Ethics Board (Queen's University), respectively.

Biochemical Quantification of Accumulated Tissue

After harvest, constructs were cut out of the culture inserts, blotted dry, weighed (wet weight), digested by papain $\left(40 \mu \mathrm{g} / \mathrm{mL}\right.$ in $20 \mathrm{mM}$ ammonium acetate, $1 \mathrm{mM} \mathrm{EDTA}$, and $2 \mathrm{mM} \mathrm{DTT}$ ) for 48 hours at $65^{\circ} \mathrm{C}$, and stored at $-20^{\circ} \mathrm{C}$ until analysis. Aliquots of the digest were assayed separately for proteoglycan, collagen and DNA contents. The proteoglycan content was estimated by quantifying the amount of sulphated glycosaminoglycans using the dimethylmethylene blue dye binding assay (Goldberg \& Kolibas, 1990). Collagen content was estimated from the determination of the hydroxyproline content. Aliquots of the papain digest were hydrolyzed in $6 \mathrm{~N} \mathrm{HCl}$ at $110^{\circ} \mathrm{C}$ for 18 hours and the hydroxyproline content of the hydrolyzate was then determined using chloramine-T/Ehrlich's reagent assay (Woessner, 1961). Collagen content was estimated assuming hydroxyproline accounts for $10 \%$ of the total collagen mass in cartilage (Heinegard et al. , 1998). The DNA content was also determined from the papain digest using the Hoechst dye 33258 assay (Kim et al. , 1988). 


\section{Histological and Immunohistochemical Assessment}

Representative constructs were harvested and fixed overnight in $4 \%$ paraformaldehyde (0.1 M phosphate buffer, $\mathrm{pH}$ 7.2), processed in graded solvents and embedded in paraffin. Thin (5 $\mu \mathrm{m})$ sections were cut and mounted on Superfrost slides (Fisher Scientific) and dried for 24 hours at $37^{\circ} \mathrm{C}$. Sections were stained with safranin-O (proteoglycans) and sirius red (collagen) or assessed for localization of collagen types I and II by immunohistochemistry, as described previously (Khan et al. , 2009). Briefly, sections were deparaffinized, rehydrated, and then treated for antigen retrieval. For collagen I, sections were heated in citrate buffer (10 $\mathrm{mM}$ citric acid, $0.05 \%$ Tween $20 ; \mathrm{pH} 6$ ) at $95-100^{\circ} \mathrm{C}$ for 20 minutes. For collagen II, sections were treated with 0.25 units $/ \mathrm{mL}$ chondroitinase $\mathrm{ABC}$ ( 1 hour) and 0.25 units $/ \mathrm{mL}$ keratinase (30 minutes) in tris-acetate buffer (40 mM tris acetate, $1 \mathrm{mM}$ EDTA; pH 8.5) at $37^{\circ} \mathrm{C}$. Sections were then blocked with $1 \%$ bovine serum albumin (BSA) in PBS for 30 minutes at room temperature and incubated with antibodies against collagen I (Abcam ab90395, 1:100 dilution) or collagen II (Developmental Studies Hybridoma Bank II-II6B3, 1:100 dilution) in $1 \% \mathrm{BSA}$ in PBS, at $4^{\circ} \mathrm{C}$ overnight. Sections were then incubated with Texas Red-labelled goat anti-mouse secondary antibody (Abcam ab6787, 1:200 dilution in 1\% BSA in PBS) for 2 hours at room temperature. Sections were counterstained with DAPI mounting medium (Vector Laboratories), and imaged (ZOE Fluorescent Cell Imager). Negative controls were performed by replacing primary antibodies with $1 \%$ BSA in PBS, with no staining detected.

\section{Glucose Metabolism}

Extracellular metabolites (glucose, lactate, $\mathrm{O}_{2}, \mathrm{CO}_{2}$ ) and $\mathrm{pH}$ were determined in the conditioned media obtained from the last exchange cycle (after 48 hours) of the 4-week culture period. Glucose and lactate in the media were detected using enzymatic assays (Lockridge et al. , 1972; Blake \& McLean, 1989) and expressed in terms of consumption or production. Changes in metabolism were then assessed by determining the yield of lactate-on-glucose ( $\mathrm{Y}_{\mathrm{L} / \mathrm{G}}$; with 2 representing $100 \%$ anaerobic metabolism) as well as relative changes in $\mathrm{O}_{2}$ consumption $\left(\mathrm{qO}_{2}\right)$ and $\mathrm{CO}_{2}$ production $\left(\mathrm{qCO}_{2}\right)$, estimated from $\mathrm{pO}_{2}$ and $\mathrm{pCO}_{2}$ levels (Radiometer ABL825). All results were normalized to DNA content.

\section{HIF-1 $\alpha$ Stabilization and Function}

The resultant effect on PHD2 activity was determined using a fluorescence-based assay (McNeill et al. , 2005) and the HIF-1 $\alpha$ 556-574 peptide substrate (containing the PHD2 hydroxylation site; 19-mer fragment; AnaSpec) in cytoplasmic extracts. Resultant effect on HIF-1 $\alpha$ stabilization was then determined by stainfree, semi-quantitative Western blotting (WB) (Zhu et al. , 2009). Briefly, protein extracts were separated using stain-free, tris/glycine $12 \%$ polyacrylamide gels and imaged before and after transfer to nitrocellulose and blotting (ChemiDoc; Bio-Rad) to determine expressed protein levels relative to the total loaded protein in the gel.

Expression of selected gene targets of HIF-1 $\alpha$ and chondrogenesis (Table S2) were determined by real-time quantitative PCR (qPCR) (Brenneret al. , 2014). Briefly, harvested constructs were snap frozen (liquid $\mathrm{N}_{2}$ ), and total RNA was extracted (RNeasy Mini Kit; Qiagen) and reversed transcribed (SuperScript III Reverse Transcriptase; Invitrogen). qPCR was performed using an ABI ViiA PCR system (ThermoFisher) with the Power SYBR Green PCR Master Mix (Applied Biosystems) and 18S (ribosomal RNA) as the endogenous (internal) control (Brenner et al. , 2014). PCR primers were constructed using Primer-BLAST (NCBI) and published mRNA sequences (NIH GenBank). Expression levels were calculated using the $\Delta \Delta \mathrm{C}_{\mathrm{T}}$ method.

Loss-of-function studies were also conducted using YC-1 to degrade HIF-1 $\alpha$ (Chun et al. , 2001) with the resultant effect on extracellular matrix synthesis determined by radioisotope incorporation (Waldman et al. , 2003). After 4 weeks of culture, samples were incubated in YC-1 (10 $\mu \mathrm{M})$ for 48 hours in the presence of $\left[{ }^{3} \mathrm{H}\right]$-proline (to quantify synthesis of collagen) and $\left[{ }^{35} \mathrm{~S}\right]$-sulfate (to quantify synthesis of proteoglycans) $(2.5 \mu \mathrm{Ci}$ each isotope; Perkin Elmer). After incubation, cultures were washed to remove unincorporated isotope and digested in papain (refer to Biochemical Quantification of Accumulated Tissue ) with aliquots 
used for $\beta$-liquid scintillation counting (Beckman Coulter). Isotope incorporation was expressed relative to DNA content (refer to Biochemical Quantification of Accumulated Tissue) and expressed relative to the controls.

\section{Quantification of Intracellular Metabolites}

Constructs were also harvested to determine potential correlations between intracellular metabolites and PHD2 activity. Briefly, harvested constructs were cut from the culture inserts, snap frozen (liquid $\mathrm{N}_{2}$ ) and stored at $-80^{\circ} \mathrm{C}$ until analysis. Using a targeted metabolomics approach, intracellular metabolites were extracted by $\mathrm{KOH} /$ ethanol $(0.3 \mathrm{M} \mathrm{KOH}$ in $25 \%$ ethanol), neutralized with glacial acetic acid, and then quantified by liquid chromatography tandem quadrupole mass spectrometry (LC/MS/MS) (Luo et al. , 2007) (Agilent 1100 HPLC/Sciex Q4000 Mass Spectrometer). A total of 14 metabolites (Table S1), representative of glycolysis, fermentation, TCA, and pentose phosphate pathways, were quantified with results expressed relative to DNA content.

Statistical Analyses

All quantitative results were expressed as mean \pm standard error of the mean (SEM). Collected data were analyzed statistically using SPSS (version 17) using a one-way ANOVA and the Tukey's post hoc testing for subsequent pair-wise comparisons. Data were checked prior to performing statistical tests for both normality (Shapiro-Wilk) and equal-variance (Levene's). Spearman rank correlation analysis was used to determine potential correlations between metabolites and PHD2 activity. Significance for all tests was associated with $p$-values less than 0.05 .

\section{Results}

\section{Effect of Nutrient Availability on Tissue Formation}

To determine the effect of nutrient availability on cartilaginous tissue formation, isolated articular chondrocytes were seeded in high-density $3 \mathrm{D}$ culture and maintained in varying amounts of media $(1-8 \mathrm{~mL}$ or $0.5-4 \mathrm{~mL} / 10^{6}$ cells) under normoxic conditions for a period of 4 weeks. Increasing media availability appeared to significantly accelerate cartilaginous tissue deposition, as demonstrated by the changes in construct mass and ECM accumulation compared to $1 \mathrm{~mL}$ control (Figure 1a, Table 1). The observed response was non-monotonic with intermediate media volumes $\left(4 \mathrm{~mL}\right.$ or $2 \mathrm{~mL} / 10^{6}$ cells) eliciting the greatest effect on both GAG and collagen deposition (3.5-fold and 2.2-fold increase, respectively) without associated increases in cellularity (Figure 1a, Table 1). Histological assessment revealed similar trends with maximal tissue thickness $(\sim 0.5 \mathrm{~mm})$ achieved under intermediate media volumes. Under all media volumes investigated, there were no observed changes in phenotype (Figure 1b) with tissue constructs staining positive for sulphated proteoglycans and collagen. Further analysis of collagen deposition (by immunohistochemical staining) indicated that the accumulated ECM was primarily collagen II, with only sporadic intracellular staining observed for collagen I. Finally, similar studies with rabbit and human chondrocytes (Figure S1) displayed strikingly similar trends suggesting this effect is conserved across different species.

Effect of Nutrient Availability on Glucose Metabolism

To investigate the potential relationship with glucose metabolism, analyses of extracellular metabolites (glucose, lactate, $\mathrm{O}_{2}, \mathrm{CO}_{2}$ ) in the conditioned media obtained from the final exchange cycle of the culture period were conducted. Glucose consumption and lactate production (Table 1) followed similar trends to the tissue formation results, with maximal consumption/production occurring under intermediate media volumes (Table 1). Under low to intermediate media volumes $(1-4 \mathrm{~mL})$ metabolism was primarily anaerobic as indicated by the high lactate-on-glucose yield $\left(\mathrm{Y}_{\mathrm{L} / \mathrm{G}}\right)$ and relatively low magnitude of $\mathrm{O}_{2}$ consumption and $\mathrm{CO}_{2}$ production (Table 1). However, larger media volumes $(>4 \mathrm{~mL})$ appeared to alter metabolism from primarily anaerobic to mixed aerobic-anaerobic with a steep decline in $\mathrm{Y}_{\mathrm{L} / \mathrm{G}}$ as well as observed increases in $\mathrm{O}_{2} / \mathrm{CO}_{2}$ consumption/production (Table 1). Lastly, extracellular $\mathrm{pH}$ did not follow a similar trend, but rather experienced monotonic increases (alkaline) with increasing media volume (Table 1). 


\section{Intersection between Glucose Metabolism and the HIF-1 $\alpha$ Pathway}

The next series of experiments were aimed at confirming the effect on HIF-1 $\alpha$ signaling by determining the changes in PHD2 enzymatic activity, HIF-1 $\alpha$ protein expression, and the expression of selected HIF-1 $\alpha$ target genes. At, and beyond, the transition from anaerobic to mixed aerobic-anaerobic metabolism ([?] 4 $\mathrm{mL}$ ), intracellular pyruvate, PHD2 activity, and HIF-1 $\alpha$ protein expression were significantly affected (Figure 2a). Similar to the tissue formation and glucose metabolism studies, maximal changes were also observed under intermediate volumes of media (4 mL) (PHD2 activity : -45\%, HIक-1a : 8-fold increase) (Figure 2a). Corresponding HIF-1 $\alpha$ gene targets (GLUT1, PDK1 and SOX9) were also maximally upregulated under these conditions (2.0- to 2.5-fold increases) (Figure 2b). Loss-of-function experiments utilizing YC-1 to degrade HIF-1 $\alpha$ paralleled these results, with maximal inhibition of ECM synthesis occurring at $4 \mathrm{~mL}(\sim 70 \%$ reduction in collagen and proteoglycan synthesis) (Figure 3). Lastly, HIF-1 $\alpha$ expression (by Western blot) after treatment with YC-1 was not detectable (data not shown).

A targeted metabolomic approach was undertaken to determine whether intracellular metabolites of glucose metabolic pathways (glycolysis, fermentation, TCA, and pentose phosphate pathways) were correlated with PHD2 activity. Of the 14 intracellular metabolites investigated, only lactate and succinate appeared to be significantly correlated with PHD2 activity $(\mathrm{p}<0.02$; Table S3). Both intracellular lactate and succinate had strong negative correlations with PHD2 activity $(\rho=-0.999$ and -0.986 , respectively) with maximal changes also observed under intermediate media volumes $(4 \mathrm{~mL})$ (lactate : 2-fold increase, succinate : 1.6 fold increase) (Figure 4). However, the relative concentrations of these metabolites were different, with lactate present in substantially higher amounts compared to succinate (order of $100 \mathrm{vs} 0.1 \mathrm{nmol} / \mu \mathrm{g}$ DNA).

\section{Discussion}

This study demonstrates that cartilaginous tissue formation can be significantly upregulated by controlling nutrient metabolism and that this response appears to be mediated through resultant changes in HIF-1 $\alpha$ signalling. Chondrocytes, although characteristically described as anaerobic cells (Khan et al. , 2009), appear to switch their metabolism in response to nutrient availability. Under low-to-intermediate volumes of media $\left(<2 \mathrm{~mL} / 10^{6}\right.$ cells $)$, chondrocytes display an anaerobic phenotype. At higher media volumes $\left(>2 \mathrm{~mL} / 10^{6}\right.$ cells), glucose uptake increases and metabolism switches to a mixed aerobic-anaerobic phenotype with the aerobic pathway appearing to be more utilized with further increases in media volume. This response is similar to the Crabtree effect — the phenomenon where aerobic cells also excrete fermentation products (e.g. ethanol or lactate) in the presence of oxygen and high external glucose (De Deken, 1966). While several potential mechanisms have been postulated to explain the Crabtree effect (e.g. catabolite repression, catabolite inactivation, limited respiratory capacity), recently it has been explained by the overflow of glucose metabolites caused by the saturation of TCA cycle capacity (Pronk et al. , 1996). Here, we postulate an inverse response ("inverse Crabtree effect") where under high glucose availability, increased glucose uptake leads to the saturation of the fermentation pathway causing metabolite overflow to the TCA cycle (Figure 5). However, it should be noted that additional studies to quantify metabolic pathway flux (e.g. ${ }^{13} \mathrm{C}$ flux analyses) are required to confirm this notion.

Previous studies have also shown that increased glucose uptake occurs under elevated media volumes (Heywood et al. , 2006; Suitset al. , 2008) and that metabolic switching can occur in response to glucose availability (Otte, 1991; Lee \& Urban, 1997; Heywoodet al. , 2010; Heywood et al. , 2014). Under low glucose, increases in oxidative phosphorylation have been observed, providing evidence for another Crabtree-like effect under such conditions (Otte, 1991; Lee \& Urban, 1997; Heywood et al. , 2010; Heywood et al. , 2014). Taken together, this suggests that chondrocytes may have several different metabolic phenotypes depending on the availability of glucose (in the presence of oxygen): predominantly anaerobic under intermediate glucose levels (Warburg-like effect) and increased aerobic activity under either low or high glucose levels (Crabtree-like effects).

One important consequence of changes in metabolic phenotype was the increased biosynthetic response (2.2to 3.5 -fold) observed at the transition between metabolic states ( $2 \mathrm{~mL} / 10^{6}$ cells). Previous studies have 
demonstrated that increased nutrient availability (by media volume) can improve cartilaginous tissue growth (Mauck et al. , 2003; Heywood et al. , 2006; Khan et al. , 2009; Oze et al. , 2012) as well as that chondrocytes are more synthetically active under mixed aerobic-anaerobic metabolism (Lane et al. , 1977; Obradovicet al. , 1999; Khan et al. , 2009). When cultured at, or near, the point of transition between anaerobic to mixed aerobic-anaerobic metabolism, a state of pseudo-hypoxia occurs resulting in the initiation of HIF-1 signaling leading to increased cartilaginous tissue formation. This response is believed to manifest as a result of the pooling of intracellular metabolites during the transition to different metabolic states, which in turn, can stabilize HIF-1 $\alpha$ by interfering with PHD2 (Lu et al. , 2002; Kim et al. , 2010; Ren et al. , 2011; De Saedeleer et al. , 2012; Bailey \& Nathan, 2018). Of the 14 metabolites investigated, only intracellular lactate and succinate were correlated with PHD2 activity. Both lactate (De Saedeleer et al. , 2012) and succinate (Bailey \& Nathan, 2018) can affect PHD2 enzymatic activity; however, by different means. Lactate inhibits PHD2 by competing with its substrate $\alpha$-ketoglutarate (De Saedeleer et al. , 2012) whereas succinate affects PHD2 activity through product inhibition at high concentrations (Bailey \& Nathan, 2018). While additional work is needed to determine the relative contributions of intracellular lactate and succinate pools on PHD2 activity, most likely this affect can be attributed to lactate due to observation that succinate was only present in trace amounts.

HIF-1 $\alpha$ stabilization occurred primarily at intermediate volumes, leading to the regulation of hypoxia-induced gene expression (Lu et al. , 2002; Kim et al. , 2010; Ren et al. , 2011; De Saedeleeret al. , 2012; Bailey \& Nathan, 2018). Although HIF-1 has many target genes, several support chondrogenesis and regulate cartilage homeostasis (Kim et al. , 2010), including glucose uptake (GLUT1), TCA cycle suppression (PDK1), and chondrogenic differentiation (SOX9); each of which was upregulated (by 2.0- to 2.7-fold) under these conditions. Lastly, loss of function experiments using YC-1 (to degrade HIF-1 $\alpha$ ) confirmed the involvement of the HIF-1 $\alpha$ pathway in these studies. While HIF mediated gene transcription can be induced by other factors, they most likely do not play as prominent a role in the current study. HIF- $1 \alpha$ can also be regulated by FIH-1 (factor inhibiting HIF) (Masoud \& Li, 2015). Similarly, in the presence of oxygen, FIH-1 hydroxylates HIF-1 $\alpha$ to prevent interaction with p300 and blocks transcriptional activation (Masoud \& Li, 2015); however, intracellular pyruvate does not affect FIH-1 expression (Dalgard et al. , 2004) or its activity (Hewitson et al. , 2007). Additionally, the other known HIF transcription factors (HIF-2 $\alpha$, HIF-3 $\alpha$ ) are also probably not involved as intracellular pyruvate does not affect HIF-2 $\alpha$ (Ren et al. , 2011) and HIF-3 $\alpha$ has multiple variants with different and opposing functions (Duan, 2016). Lastly, while direct hypoxia has been investigated as an anabolic stimulus for chondrocytes (Coyle et al. , 2009; Yodmuang et al. , 2013), conflicting results have been observed, most likely due to the fact that chondrocytes require oxygen to a certain degree and prolonged hypoxia has been definitively shown to inhibit ECM synthesis (Gibson et al. , 2008).

It is also recognized that other factors could potentially contribute to the observed response. To account for changes in hydrostatic pressure between cultures of different media volumes, these studies were conducted using different sized culture plates (i.e. 24-, 12- and 6-well plates). Estimates of the maximum hydrostatic pressure difference between conditions were relatively small ([?] $50 \mathrm{~Pa})$ due to the minimal changes in media height above the cultures ([?] $5 \mathrm{~mm}$ ). Previous studies have shown that hydrostatic pressures of several orders of magnitude higher ( $\mathrm{kPa}$ to $\mathrm{MPa}$ range) are required to elicit changes in ECM synthesis (anabolic or catabolic) (Elder \& Athanasiou, 2009) indicating that the potential influences were negligible. Limitations in oxygen delivery to the cultures can also be a concern with varying culture volumes (Place et al. , 2017). However, the distance from the cells to the media surface was also accounted for by using different sized culture plates and held relatively constant across groups (within $5 \mathrm{~mm}$ ). In addition, as media buffering capacity changes proportionally with volume, there may have been an influence of extracellular $\mathrm{pH}$. Chondrocytes are sensitive to $\mathrm{pH}$ with relatively small changes influencing ECM synthesis (Wilkins \& Hall, 1995). However, observed differences in extracellular $\mathrm{pH}$ did not correlate with the changes in ECM deposition, which was maximal at intermediate media volumes. Lastly, as the cultures were only evaluated after a 4-week culture period (or the last 48-hour media exchange cycle), additional studies are required to determine whether these effects manifest throughout the culture period.

\section{Conclusions}


The results of this study demonstrate that cartilaginous tissue formation can be upregulated through the control of nutrient metabolism and that the observed response is mediated through resultant changes in HIF$1 \alpha$ signalling. By culturing in elevated volumes of media, glucose uptake by chondrocytes is increased, leading to a change in metabolism from primarily anaerobic to mixed aerobic-anaerobic (inverse Crabtree effect). When cultured at the transition between metabolic states, a pseudo-hypoxic state is induced resulting in HIF$1 \alpha$ mediated gene transcription and an associated increase in chondrogenesis. These findings represent a novel, paradigm-shifting approach to develop functional engineered cartilage implants that can be produced without sophisticated stimulation methods. The developed methodology is highly transferable and can be applied to any cartilage tissue engineering approach. Such methods are attractive as they have fewer regulatory barriers to aid commercialization efforts, thereby allowing for improved clinical translation. Additionally, these newly identified metabolic pathways could potentially provide insights into the mechanisms of cartilage growth and development. Future avenues of research will include metabolic modelling (e.g. ${ }^{13} \mathrm{C}$ flux analyses) to provide a framework to control chondrogenesis.

\section{Acknowledgements}

Funding for this work was provided by the Canadian Institutes of Health Research (CIHR).

\section{Author Contributions}

Conception and design: RT SDW. Acquisition of data: RT LLYC JFW MYT DDB SCP. Analysis and interpretation of the data: RT LLYC SDW. Obtaining of funding: SDW. Drafting of the article: RT LLYC SDW. Critical revision of the article for important intellectual content: JFW MYT DDB SCP. Final approval of the article: RT LLYC JFW MYT DDB SCP SDW.

\section{Conflict of Interest}

None.

\section{References}

Bailey, P.S.J., \& Nathan, J.A. (2018). Metabolic regulation of hypoxia-inducible transcription factors: the role of small molecule metabolites and iron. Biomedicines , 6, 60 .

Blake, D.A., \& McLean, N.V. (1989). Colorletric assay for the measurement of D-glucose consumption in cultured cells. Analytical Biochemistry , 177, 156-160.

Brenner, J.M., Ventura, N.M., Tse, M.Y., Winterborn, A., Bardana, D.D., Pang, S.C., Hurtig. M.B., \& Waldman, S.D. (2014). Implantation of scaffold-free engineered cartilage constructs in a rabbit model for chondral resurfacing. Artifical Organs, 38, E21-E32.

Brittberg, M., Lindahl, A., Nilsson, A., Ohlsson, C., Isaksson, O., \& Peterson, L. (1994). Treatment of deep cartilage defects in the knee with autologous chondrocyte transplantation. New England Journal of Medicine ,331, 889-895.

Buschmann, M.D., Gluzband, Y.A., Grodzinsky, A.J., Kimura, J.H., \& Hunziker, E.B. (1992). Chondrocytes in agarose culture synthesize a mechanically functional extracellular matrix. Journal of Orthopaedic Research , 10, 754-758.

Chen, J.L., Duan, L., Zhu, W., Xiong, J., \& Wang, D. (2014). Extracellular matrix production in vitro in cartilage tissue engineering. Journal of Translational Medicine , 12, 88-96.

Chun, Y.S., Yeo, E.J., Choi, E., Teng, C.M., Bae, J.M., Kim, M.S., \& Park, J.W. (2001). Inhibitory effect of YC-1 on the hypoxic induction of erythropoietin and vascular endothelial growth factor in Hep3B cells.Biochemical Pharmacology , 61, 947-954.

Coyle, C.H., Izzo, N.J., \& Chu, C.R. (2009). Sustained hypoxia enhances chondrocyte matrix synthesis. Journal of Orthopaedic Research , 27, 793-799. 
Dalgard, C.L., Lu, H., Mohyeldin, A., \& Verma, A. (2004). Endogenous 2-oxoacids differentially regulate expression of oxygen sensors. Biochemistry Journal , 380, 419-424.

De Deken, R.H. (1966). The Crabtree effect: a regulatory system in yeast. Journal of General Microbiology, 44, 149-156.

Dengler, V.L., Galbraith, M.D., \& Espinosa, J.M. (2014). Transcriptional regulation by hypoxia inducible factors. Critical Reviews in Biochemistry and Molecular Biology, 49, 1-15.

De Saedeleer, C.J., Copetti, T., Porporato, P.E., Verrax, J., Feron, O., \& Sonveaux, P. (2012). Lactate activates HIF-1 in oxidative but not in Warburg-phenotype human tumor cells. PLoS One , 7, e46571.

Duan, C. (2016). Hypoxia-inducible factor 3 biology: complexities and emerging themes. American Journal of Physiology - Cell Physiology , 310, C260-C269.

Elder, B.D., \& Athanasiou, K.A. (2009). Hydrostatic pressure in articular cartilage tissue engineering: from chondrocytes to tissue regeneration. Tissue Engineering Part B , 15, 43-53.

Gibson, J.S., Milner, P.I., White, R., Fairfax, T.P.A., \& Wilkins, R.J. (2008). Oxygen and reactive oxygen species in articular cartilage: modulators of ionic homeostasis. Pflugers Archives , 455, 563-573.

Goldberg, R.L., \& Kolibas, L.M. (1990). An improved method for determining proteoglycans synthesized by chondrocytes in culture. Connective Tissue Research , 24, 265-275.

Goldring, M.B., \& Marcu, K.B. (2009). Cartilage homeostasis in health and rheumatic diseases.Arthritis Research and Therapy, 11, 224.

Heinegard, D., Bayliss, M., \& Lorenzo, P. (1998). Biochemistry and metabolism of normal and osteoarthritic cartilage. In Brandt, K.D., Doherty, M., Lohmander, L.S., eds. Osteoarthritis. New York, NY: Oxford University Press, 74-84.

Hewitson, K.S., Liénard, B.M., McDonough, M.A., Clifton, I.J., Butler, D., Soares, A.S., Oldham, N.J., McNeill, L.A., \& Schofield, C.J. (2007). Structural and mechanistic studies on the inhibition of the hypoxiainducible transcription factor hydroxylases by tricarboxylic acid cycle intermediates. Journal of Biological Chemistry, 282, 3293-3301.

Heywood, H.K., Bader, D.L., \& Lee, D.A. (2006). Glucose concentration and medium volume influence cell viability and glycosaminoglycan synthesis in chondrocyte-seeded alginate constructs. Tissue Engineering , $12,3487-3496$.

Heywood, H.K., Knight, M.M., \& Lee, D.A. (2010). Both superficial and deep zone articular chondrocyte subpopulations exhibit the Crabtree effect but have different basal oxygen consumption rates. Journal of Cellular Physiology, 223, 630-639.

Heywood, H.K., Nalesso, G., Lee, D.A., \& Dell'accio, F. (2014). Culture expansion in low-glucose conditions preserves chondrocyte differentiation and enhances their subsequent capacity to form cartilage tissue in three-dimensional culture. Bioresearch Open Access , 3, 9-18.

Hunziker, E.B. (1999). Articular cartilage repair: are the intrinsic biological constraints undermining this process insuperable? Osteoarthritis and Cartilage, 7, 15-28.

Kaupp, J.A., \& Waldman, S.D. (2008). Mechanical vibrations increase the proliferation of articular chondrocytes in high-density culture. Proceedings of the Institution of Mechanical Engineering Part H , 222, 695-703.

Khan, A.A., Suits, J.M., Kandel, R.A., \& Waldman, S.D. (2009). The effect of continuous culture on the growth and structure of tissue-engineered cartilage. Biotechnology Progress , 25, 508-515.

Kim, Y.J., Sah, R.L., Doong, J.Y., \& Grodzinsky, A.J. (1988). Fluorometric assay of DNA in cartilage explants using Hoechst 33258. Analytical Biochemistry , 174, 168-176. 
Kim, S.Y., Choi, J.S., Park, C., \& Jeong, J.W. (2010). Ethyl pyruvate stabilizes hypoxia-inducible factor 1 alpha via stimulation of the TCA cycle. Cancer Letters, 295, 236-241.

Lam, J., Lu, S., Kasper, F.K., \& Mikos, A.G. (2015). Strategies for controlled delivery of biologics for cartilage repair. Advanced Drug Delivery Reviews , 84, 123-134.

Lane, J.M., Brighton, C.T., \& Menkowitz, B.J. (1977). Anaerobic and aerobic metabolism in articular cartilage. Journal of Rheumatology, 4, 334-342.

Lee, R.B., \& Urban, J.P. (1997). Evidence for a negative Pasteur effect in articular cartilage. Biochem Journal , 321, 95-102.

Lockridge, O., Massey, V., \& Sullivan, P.A. (1972). Mechanism of action of the flavoenzyme lactate oxidase. Journal of Biological Chemistry , 247, 8097-8106.

Lu, H., Forbes, R.A., \& Verma, A. (2002). Hypoxia-inducible factor 1 activation by aerobic glycolysis implicates the Warburg effect in carcinogenesis. Journal of Biological Chemistry, 277, 23111-23115.

Luo, B., Groenke, K., Takors, R., Wandrey, C., Oldiges, M. (2007). Simultaneous determination of multiple intracellular metabolites in glycolysis, pentose phosphate pathway and tricarboxylic acid cycle by liquid chromatography-mass spectrometry. Journal of Chromatography A , 1147, 153-164.

Masoud, G.N., \& Li, W. (2015). HIF-1 $\alpha$ pathway: role, regulation and intervention for cancer therapy. Acta Pharmaceutica Sinica B , 5, 378-389.

Mauck, R.L., Wang, C.C., Oswald, E.S., Ateshian, G.A., \& Hung, C.T. (2003). The role of cell seeding density and nutrient supply for articular cartilage tissue engineering with deformational loading. Osteoarthritis and Cartilage, 11, 879-890.

McNeill, L.A., Bethge, L., Hewitson, K.S., \& Schofield, C.J. (2005). A fluorescence-based assay for 2oxoglutarate-dependent oxygenases. Analytical Biochemistry , 336, 125-131.

Obradovic, B., Carrier, R.L., Vunjak-Novakovic, G., \& Freed, L.E. (1999). Gas exchange is essential for bioreactor cultivation of tissue engineered cartilage. Biotechnology and Bioengineering , 63, 197-205.

Otte, P. (1991). Basic cell metabolism of articular cartilage. Manometric studies. Zeitschrift für Rheumatologie , 50, 304-312.

Oze, H., Hirao, M., Ebina, K., Shi, K., Kawato, Y., Kaneshiro, S., Yoshikawa, H., \& Hashimoto, J. (2012). Impact of medium volume and oxygen concentration in the incubator on pericellular oxygen concentration and differentiation of murine chondrogenic cell culture.In Vitro Cellular 83 Developmental Biology Animal , 48, 123-130.

Place, T.L., Domann, F.E., \& Case, A.J. (2017). Limitations of oxygen delivery to cells in culture: An underappreciated problem in basic and translational research. Free Radical Biology 83 Medicine, 113, 311322.

Pronk, J.T., Yde Steensma, H., \& Van Dijken, J.P. (1996). Pyruvate metabolism in Saccharomyces cerevisiae. Yeast , 12, 1607-1633.

Ren, H., Liu, N.Y., Song, X.F., Ma, Y.S., \& Zhai, X.Y. (2011). A novel specific application of pyruvate protects the mouse retina against white light damage: differential stabilization of HIF-1 $\alpha$ and HIF$2 \alpha$.Investigative Ophthalmology \& Vision Science, 52, 3112-3118.

Suits, J.M., Khan, A.A., \& Waldman, S.D. (2008). Glycogen storage in tissue-engineered cartilage. Tissue Engineering and Regenerative Medicine, 2, 340-346.

Vunjak-Novakovic, G., Martin, I., Obradovic, B., Treppo, S., Grodzinsky, A.J., Langer, R., \& Freed, L.E. (1999). Bioreactor cultivation conditions modulate the composition and mechanical properties of tissueengineered cartilage. Journal of Orthopaedic Research , 17, 130-138. 
Waldman, S.D., Grynpas, M.D., Pilliar, R.M., \& Kandel, R.A. (2002). Characterization of cartilagenous tissue formed on calcium polyphosphate substrates in vitro. Journal of Biomedical Materials Research , 62, 323-330.

Waldman, S.D., Spiteri, C.G., Grynpas, M.D., Pilliar, R.M., \& Kandel, R.A. (2003). Long-term intermittent shear deformation improves the quality of cartilaginous tissue formed in vitro. Journal of Orthopaedic Research , 21, 590-596.

Wilkins, R.J., \& Hall, A.C. (1995). Control of matrix synthesis in isolated bovine chondrocytes by extracellular and intracellular pH.Journal of Cellular Physiology , 164, 474-81.

Woessner, J.F. (1961). The determination of hydroxyproline in tissue and protein samples containing small proportions of this amino acid.Archives of Biochemistry and Biophysics , 93, 440-447.

Yodmuang, S., Gadjanski, I., Chao, P.H., \& Vunjak-Novakovic, G. (2013). Transient hypoxia improves matrix properties in tissue engineered cartilage. Journal of Orthopaedic Research, 31, 544-553.

Zhu, G., Tang, Y., Liang, X., Zheng, M., Yang, J., Zhou, H., Li, L., \& Qin, T. (2009). Role of hypoxiainducible factor-1 alpha in the regulation of plasminogen activator activity in rat knee joint chondrocytes. Osteoarthritis and Cartilage, 17, 1494-1502.

\section{Figure Captions}

\section{Figure 1}

Effect of media volume on tissue formation. (A) Biochemical accumulation of cartilaginous constituents (GAG, collagen and DNA). (B) Histological (sulphated proteoglycan stain: safranin-O ; collagen stain:sirius red ) and immunohistochemical (collagen I and collagen II) appearance of the developed tissue constructs. Data presented as mean \pm SEM, normalized to $1 \mathrm{~mL}$ control $(\mathrm{n}=6 /$ group $){ }^{\text {a }}$ significantly different $(\mathrm{p}<0.05)$; all scale bars: $150 \mu \mathrm{m}$.

\section{Figure 2}

Effect of media volume on metabolic pathway activity and stabilization of HIF-1 $\alpha$. (A) Intracellular pyruvate ( $\mathrm{n}=4$ /group), PHD2 activity ( $\mathrm{n}=3$ /group), and HIF-1 $\alpha$ expression ( $\mathrm{n}=3 /$ group). Biochemical data normalized to $1 \mathrm{~mL}$. (B) Selected gene targets of HIF-1 $\alpha$ (SOX9, PDK1, GLUT1) (n=3/group). qPCR expression calculated using the $\Delta \Delta \mathrm{C}_{\mathrm{T}}$ method. Data presented as mean $\pm \mathrm{SEM}{ }^{\mathrm{a}}$ significantly different from $1 \mathrm{~mL}$ $(\mathrm{p}<0.05) ;{ }^{\mathrm{b}}$ significantly different from $1 \mathrm{~mL}$ and $2 \mathrm{~mL}(\mathrm{p}<0.05) ;{ }^{*}$ significantly different from all other groups $(\mathrm{p}<0.05)$.

\section{Figure 3}

Effect of YC-1 on ECM synthesis. $2 \mathrm{~mL}$ group was not investigated due to the general lack of differences from $1 \mathrm{~mL}$. Data presented as mean $\pm \mathrm{SEM}$, normalized to $1 \mathrm{~mL}$ control $(\mathrm{n}=4 /$ group$) ;{ }^{\text {a }}$ significantly different from no YC-1 control $(\mathrm{p}<0.05)$.

\section{Figure 4}

Effect of media volume on intracellular lactate and succinate. Data presented as mean \pm SEM, normalized to $1 \mathrm{~mL}$ control ( $\mathrm{n}=4 /$ group). ${ }^{\mathrm{a}}$ significantly different from $1 \mathrm{~mL}(\mathrm{p}<0.05)$.

\section{Figure 5}

Proposed mechanism illustrating the intersection between glucose metabolism and the HIF-1 $\alpha$ pathway. At the transition from anaerobic to mixed anaerobic-aerobic metabolism, intracellular lactate concentration is maximal. In the presence of oxygen, the accumulation of lactate stabilizes the transcription factor HIF- $1 \alpha$ (hypoxia inducible factor $1 \alpha$ ) by interfering with proline-hydroxylase-2 (PHD2), resulting in the regulation of hypoxia-induced gene expression independent of hypoxia (pseudo-hypoxia).

Figure 1 
A

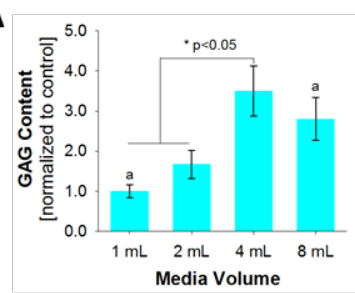

B
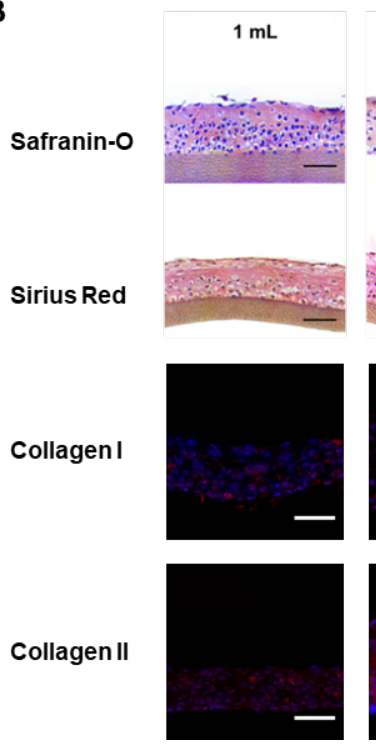
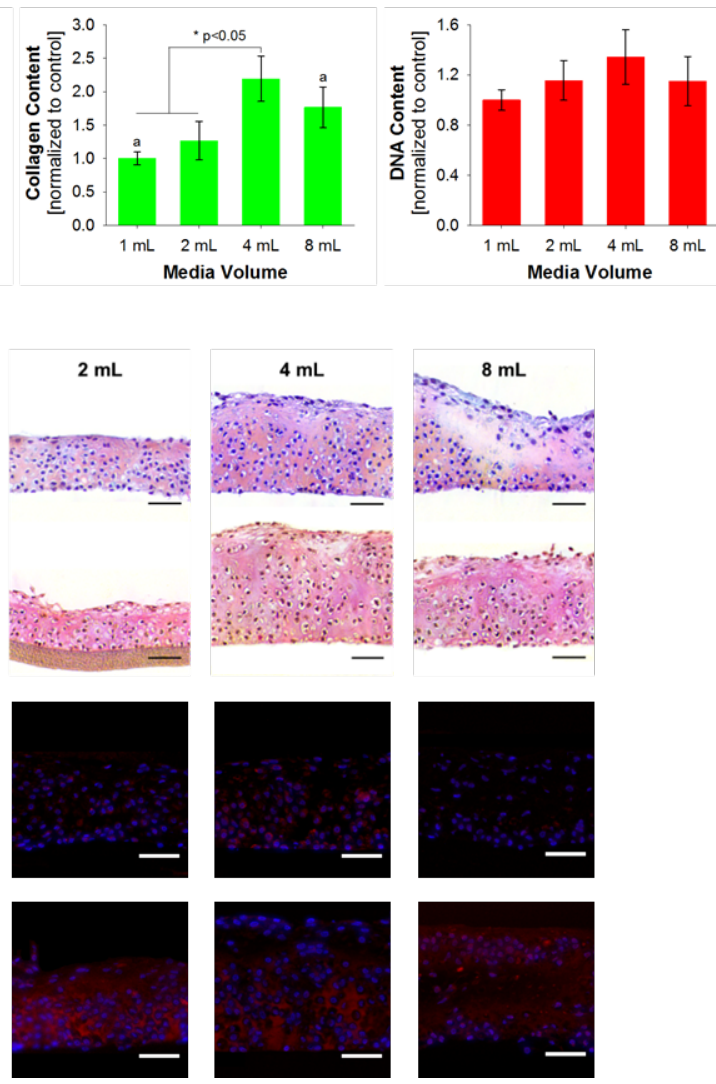

Figure 2
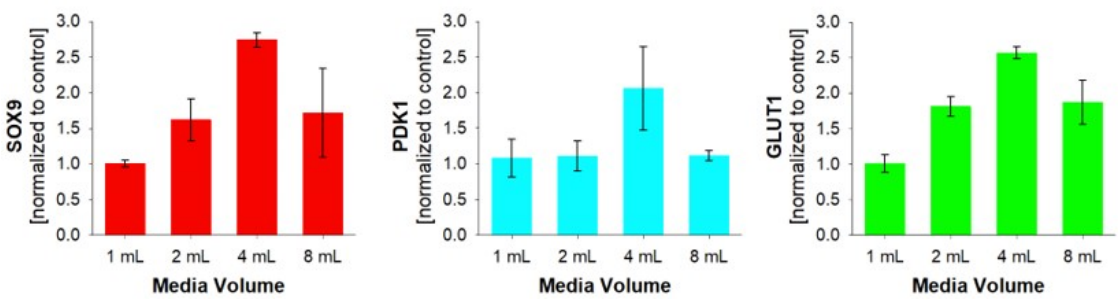

Figure 3

\section{Hosted file}

image4.emf available at https://authorea.com/users/391261/articles/505429-effect-ofnutrient-metabolism-on-cartilaginous-tissue-formation

\section{Figure 4}

\section{Hosted file}

image5.emf available at https://authorea.com/users/391261/articles/505429-effect-ofnutrient-metabolism-on-cartilaginous-tissue-formation 


\section{Figure 5}

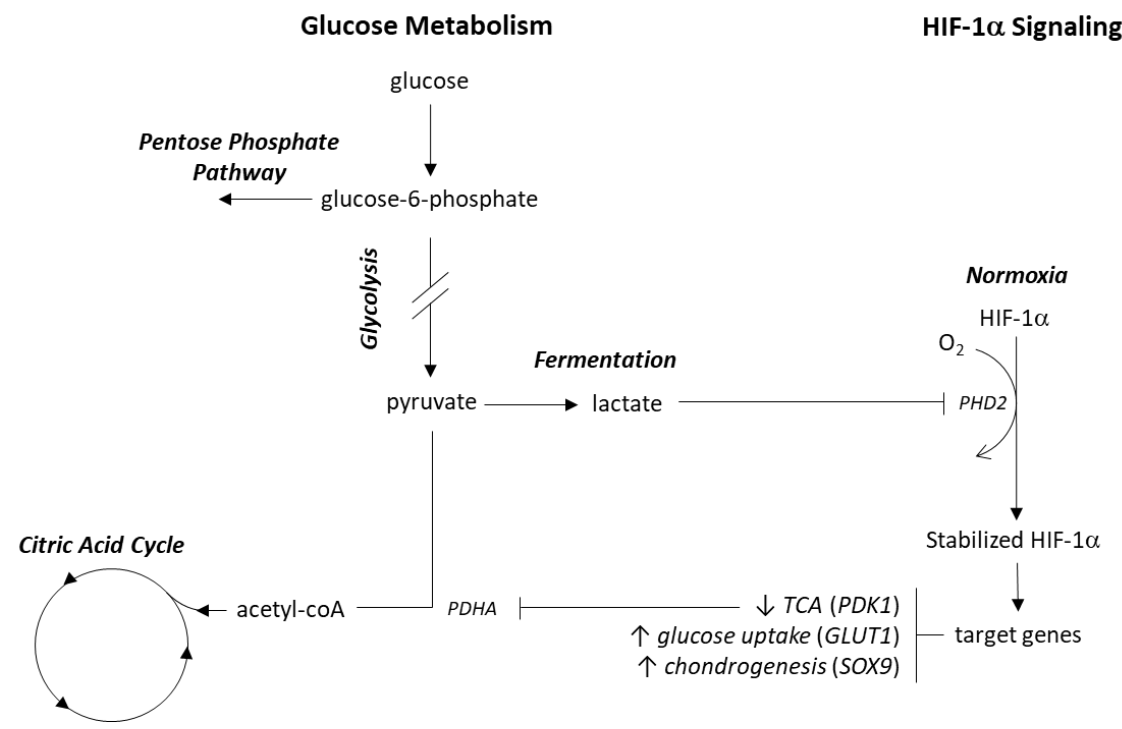

Tables

Table 1 : Effect of media volume on ECM accumulation and glucose metabolism.

\begin{tabular}{|c|c|c|c|c|}
\hline & Media Volume & Media Volume & Media Volume & Media Volume \\
\hline & $1 \mathrm{~mL}$ & $2 \mathrm{~mL}$ & $4 \mathrm{~mL}$ & $8 \mathrm{~mL}$ \\
\hline Wet Weight [normalized to control $(1 \mathrm{~mL})]$ & $1.00 \pm 0.09 *$ & $1.42 \pm 0.08^{\mathrm{a}}$ & $2.4 \pm 0.3^{*}$ & $2.0 \pm 0.2$ \\
\hline GAG/DNA [normalized to control $(1 \mathrm{~mL})]$ & $1.00 \pm 0.11 *$ & $1.61 \pm 0.22^{\mathrm{a}}$ & $3.30 \pm 0.41$ & $2.78 \pm 0.23$ \\
\hline Collagen/DNA [normalized to control $(1 \mathrm{~mL})]$ & $1.00 \pm 0.09 *$ & $1.35 \pm 0.40^{+}$ & $2.26 \pm 0.63^{+}$ & $2.03 \pm 0.69$ \\
\hline Glucose Consumption $[\mathrm{nmol} / \mathrm{h} / \mu \mathrm{g}$ DNA] & $15 \pm 2^{\mathrm{a}}$ & $25 \pm 3^{\mathrm{a}}$ & $63 \pm 25^{\mathrm{b}}$ & $53 \pm 13^{\mathrm{b}}$ \\
\hline Lactate Production $[\mathrm{nmol} / \mathrm{h} / \mu \mathrm{g}$ DNA $]$ & $28 \pm 3^{\mathrm{a}}$ & $45 \pm 7^{\mathrm{a}}$ & $105 \pm 39^{b}$ & $83 \pm 21^{b}$ \\
\hline $\mathrm{Y}_{\mathrm{L} / \mathrm{G}}$ (yield of lactate-on-glucose)+ & $1.88 \pm 0.03^{+}$ & $1.75 \pm 0.09$ & $1.74 \pm 0.06$ & $1.55 \pm 0.06^{+}$ \\
\hline Extracellular $\mathrm{pH}$ & $6.62 \pm 0.04$ & $6.70 \pm 0.04$ & $6.86 \pm 0.04 *$ & $7.05 \pm 0.05 *$ \\
\hline $\mathrm{O}_{2}$ Consumption $\left(\mathrm{qO}_{2}\right)[\mathrm{nmol} / \mathrm{h} / \mu \mathrm{g}$ DNA $]$ & $0.23 \pm 0.04^{\mathrm{a}}$ & $0.43 \pm 0.05^{\mathrm{a}}$ & $0.84 \pm 0.08^{b}$ & $1.2 \pm 0.1^{\mathrm{b}}$ \\
\hline $\mathrm{CO}_{2}$ Production $\left(\mathrm{qCO}_{2}\right)[\mathrm{nmol} / \mathrm{h} / \mu \mathrm{g} \mathrm{DNA}]$ & $4.0 \pm 0.8$ & $6.7 \pm 0.5$ & $11.5 \pm 0.9$ & $27 \pm 3^{*}$ \\
\hline
\end{tabular}

* significantly different from all groups $(\mathrm{p}<0.01) ;{ }^{+}$significantly different from each other $(\mathrm{p}<0.05){ }^{\mathrm{a}}$ sig- $^{\text {- }}$ nificantly different from 4 and $8 \mathrm{~mL}(\mathrm{p}<0.05) ;{ }^{\mathrm{b}}$ significantly different from 1 and $2 \mathrm{~mL}(\mathrm{p}<0.05)$; Data presented as mean +- SEM with $\mathrm{n}=6 /$ group, except $\mathrm{qO}_{2}$ and $\mathrm{qCO}_{2}$ with $\mathrm{n}=3 /$ group $;+$ ratio of $2\left(\mathrm{Y}_{\mathrm{L} / \mathrm{G}}\right)$ indicates $100 \%$ anaerobic metabolism.

\section{Supplemental Figure Captions}

\section{Figure S1}

Effect of media volume on tissue formation from rabbit (A) and human (B) chondrocytes. Tissue engineered constructs were developed from chondrocytes of either skeletally mature New Zealand White rabbits (two female donors, $\sim 11$ months old, $\sim 4 \mathrm{~kg}$; P0 cells) or human donors (two female donors aged 45 and 47; P2 cells). Data presented as mean +- SEM, $n=4 /$ group.

\section{Supplemental Figure 1}



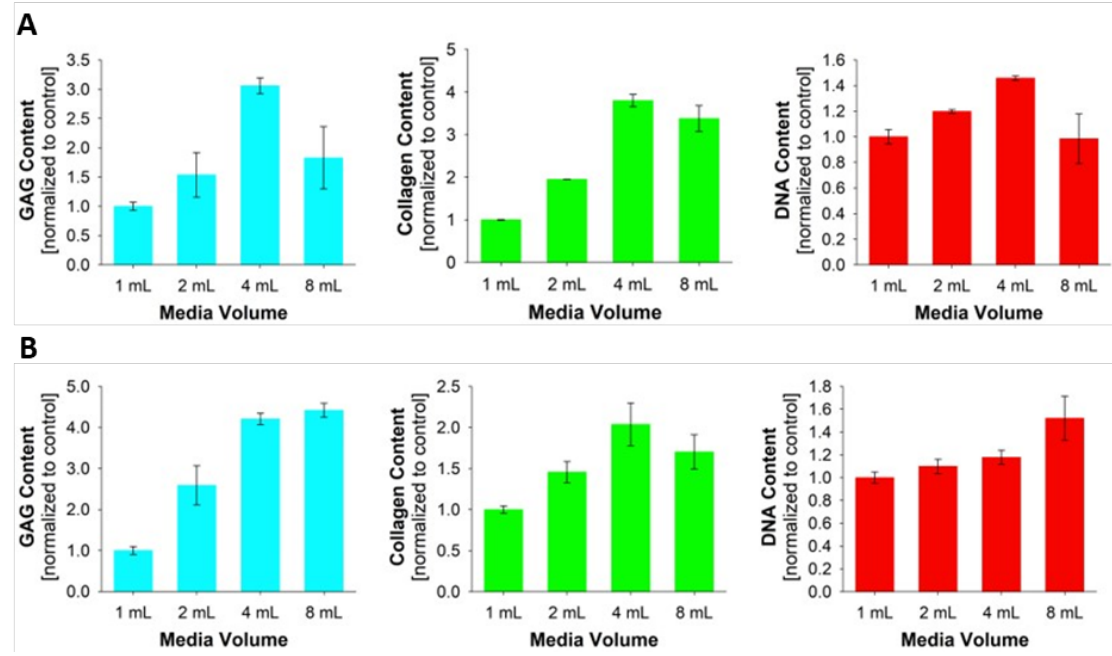

\section{Supplemental Tables}

Table S1 : Measured metabolites.

\begin{tabular}{llll}
\hline Glycolysis & Fermentation & TCA Cycle & $\begin{array}{l}\text { Pentose Phosphate } \\
\text { Pathway }\end{array}$ \\
\hline G6P F6P FBP DHAP & PYR LAC & PYR AKG SUC FUM & G6P 6GP R5P \\
3PG PEP PYR & & MAL & \\
\hline
\end{tabular}

Table S2 : PCR primers.

\begin{tabular}{lllll}
\hline Gene & Sense & Anti-Sense & Length & $\mathbf{T}_{\mathbf{m}}$ \\
\hline SOX9 & GCCGTGATTGGCCCTTGTATTTA & CCACTGAAGTTCCAGGTCAGTTTC & $93 \mathrm{bp}$ & $65^{\circ} \mathrm{C}$ \\
PDK1 & TGCTAGGCGTCTGTGTGATTTG & CTTGTATTGGCTGTCCTGGTGATT & $92 \mathrm{bp}$ & $65^{\circ} \mathrm{C}$ \\
GLUT1 & GAGGTGTCGGCGTTTGATTCTT & CACTGGCAAGCTCCACCATAAC & $104 \mathrm{bp}$ & $65^{\circ} \mathrm{C}$ \\
18S & GTGGAGCGATTTGTCTGGGTTAAT & TGAACGCCACTTGTCCCTCTAA & $120 \mathrm{bp}$ & $65^{\circ} \mathrm{C}$ \\
\hline
\end{tabular}

Table S3 : Correlation between intracellular metabolites and PHD2 activity.

\begin{tabular}{|c|c|c|c|}
\hline Metabolite & Metabolic Pathway & 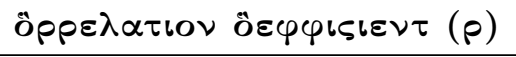 & $\mathrm{p}$-value \\
\hline G6P & Glycolysis, PPP & 0.693 & 0.407 \\
\hline F6P & Glycolysis & 0.636 & 0.465 \\
\hline $3 \mathrm{PG}$ & Glycolysis & -0.180 & 0.860 \\
\hline FBP & Glycolysis & -0.079 & 0.939 \\
\hline DHAP & Glycolysis & -0.438 & 0.648 \\
\hline PEP & Glycolysis & -0.384 & 0.694 \\
\hline LAC & Fermentation & -0.999 & 0.000 \\
\hline $6 \mathrm{PG}$ & $\mathrm{PPP}$ & 0.361 & 0.714 \\
\hline $\mathrm{R} 5 \mathrm{P}$ & PPP & -0.627 & 0.475 \\
\hline PYR & Glycolysis, Fermentation, TCA & -0.794 & 0.294 \\
\hline AKG & TCA & -0.078 & 0.940 \\
\hline
\end{tabular}




\begin{tabular}{|c|c|c|c|}
\hline Metabolite & Metabolic Pathway & 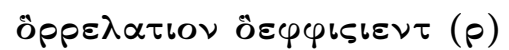 & $\overline{p \text {-value }}$ \\
\hline SUC & TCA & -0.986 & 0.017 \\
\hline FUM & TCA & -0.865 & 0.202 \\
\hline MAL & TCA & -0.767 & 0.326 \\
\hline
\end{tabular}

TCA : Tricarboxylic Acid Cycle; PPP : Pentose Phosphate Pathway 